\title{
Understanding the potential of state-based public health genomics programs to mitigate disparities in access to clinical genetic services
}

\author{
Laura Senier, $\mathrm{MPH}, \mathrm{PhD}^{1,2}$, Catherine Tan, $\mathrm{MA}^{1}$, Leandra Smollin, $\mathrm{PhD}^{3}$ and Rachael Lee, $\mathrm{MA}^{1}$
}

Purpose: State health agencies (SHAs) have developed public health genomics (PHG) programs that play an instrumental role in advancing precision public health, but there is limited research on their approaches. This study examines how PHG programs attempt to mitigate or forestall health disparities and inequities in the utilization of genomic medicine.

Methods: We compared PHG programs in three states: Connecticut, Michigan, and Utah. We analyzed 85 in-depth interviews with SHA internal and external collaborators and program documents. We employed a qualitative coding process to capture themes relating to health disparities and inequities.

Results: Each SHA implemented population-level approaches to identify individuals who carry genetic variants that increase risk of hereditary cancers. However, each SHA developed a unique strategy -which we label public health action repertoires-to reach specific subgroups who faced barriers in accessing genetic services. These strategies varied across states given demographics of the state population, state-level partnerships, and availability of healthcare services.

Conclusion: Our findings illustrate the imperative of tailoring PHG programs to local demographic characteristics and existing community resources. Furthermore, our study highlights how integrating genomics into precision public health will require multilevel, multisector collaboration to optimize efficacy and equity.

Genetics in Medicine (2019) 21:373-381; https://doi.org/10.1038/s41436018-0056-y

Keywords: Public health genomics; Precision public health; Health disparities; Determinants of health; Implementation

\section{INTRODUCTION}

Efforts to scale up genetic medicine have intensified in recent years, with much of this work focusing on its application in clinical settings; comparatively less attention has been paid to the role of public health agencies in its dissemination and implementation. ${ }^{1}$ In the United States, state health agencies (SHAs) have played an important role in disseminating best practices for genomic medicine, thus advancing precision public health. ${ }^{2}$ SHAs educate providers and the public about evidence-based guidelines for appropriate use of genomic testing and exercise leadership in workforce preparedness and policy development, but most critically, they monitor populations for emergence of health disparities, and craft and evaluate interventions to forestall the emergence of those disparities or mitigate their effects. ${ }^{3}$ This paper explains how SHA genomics program staff understand health disparities and how they have addressed the social barriers to accessing genomic services.

\section{Background}

The advent of genomics and its potential to improve risk identification and disease prevention have raised concerns about the exacerbation of health disparities and inequities, and distraction from social and environmental contributors of disease. ${ }^{4}$ While there are many competing definitions of the terms health disparities and health inequities, ${ }^{5}$ in this paper, we follow the conventions of the people we are studying. Clinicians and geneticists commonly understand health disparities as "differing health outcomes associated with population genetic variation." Health inequities, however, is more often used in public health to describe health outcomes that are avoidable and therefore considered unfair. ${ }^{5,6}$ In this paper, we show how public health genomics (PHG) staff needed to reconcile tensions between these two definitions as they crafted state-specific genomics programs.

To understand how SHA genomics programs could mitigate health inequities, we consider health promotion frameworks presented by Geoffrey Rose: a strategy for identifying high-risk individuals versus a strategy of broadbased, population-level programming. While the former strategy individualizes risk identification and intervention, the latter brings general health promotion messages to a wider audience. $^{5}$ In the case of breast cancer, for example, a population-level approach would encourage all women to get

\footnotetext{
${ }^{1}$ Department of Sociology \& Anthropology, Northeastern University, 360 Huntington Avenue, Boston, Massachusetts 02115, USA; ${ }^{2}$ Department of Health Sciences, Northeastern University, 360 Huntington Avenue, Boston, Massachusetts 02115, USA; ${ }^{3}$ Department of Sociology \& Criminal Justice, State University of New York at Potsdam, 44 Pierrepont Avenue, Potsdam, New York 13676, USA. Correspondence: Laura Senier (1.senier@northeastern.edu)
} 
mammograms biennially after 50 years of age; ${ }^{7,8}$ conversely, a high-risk strategy would identify the much smaller proportion of women who may carry genetic variants that increase risk of disease and for targeted screening at an earlier age. ${ }^{9}$

Rose's frameworks are highly influential in public health, but they are incompatible with the emerging discourse of precision public health, which proposes to tailor disease prevention to groups of people who share genes, environments, and lifestyles. ${ }^{3}$ Several commentators have tried to modify Rose's paradigm to meet the challenges of precision public health. ${ }^{10,11}$ Burton et al., for example, argue for a third framework of "stratified prevention"-to use genetic risk assessment to tailor interventions more precisely. ${ }^{10}$ For example, information about an individual's absolute risk of breast cancer over a 10 -year period could help determine the appropriate age at which mammographic screening should start. There are two important limitations to this approach, however. First, it presupposes the availability of interventions at each level of stratified risk. Second, it ignores questions about whether such interventions would be equitably available to everyone who might need them.

Moreover, although Rose contends that a population-level strategy could potentially address underlying social determinants of health, some public health scholars remain skeptical about this claim, ${ }^{12}$ especially with respect to genetic medicine. ${ }^{13-15}$ McLaren et al., for example, argue that any strategy requiring individuals to take action (e.g., behavioral changes) will widen disparities between those who have wealth and resources and those who do not. ${ }^{16}$ Accordingly, they argue that population-level strategies that target structural, contextual, and environmental factors are likelier to narrow disparities and should be prioritized in public health planning. A key example may be found in Frieden's "health impact pyramid," which illustrates the necessity of policy and environmental changes to "make the default choice the healthy one." 17 Similarly, Link and Phelan identify socioeconomic status (SES) as a "fundamental cause" because it restricts access to resources and the ability to minimize risk of disease. ${ }^{18}$ For example, in the case of breast cancer screening, social factors such as SES and race can prevent a woman from getting genetic counseling and testing, thus impeding her ability to consider riskreducing interventions, such as increased surveillance, chemoprevention, and prophylactic mastectomy. ${ }^{19}$

To be fair, Rose himself notes that both high-risk and population-level strategies are crucial for public health. ${ }^{7}$ In practice, we find that state $\mathrm{PHG}$ programs have needed to integrate both. However, because public health programming in the United States is governed at the state level, there are wide variations among states, both in terms of their capacity to act on novel health discoveries, and in the needs of their populations. Understanding these variations is a critical step in understanding the potential or limitations of strategies to prevent health inequities.

\section{State public health genomics programs}

This study tracks the development of PHG programs in three states: Michigan, Utah, and Connecticut, all of which received funding from the Centers for Disease Control and Prevention (CDC) over the past 15 years, albeit for different intervals. From 2014 to 2019, all three states received funding under the same CDC Request for Application (RFA) to promote evidence-based practices for risk-appropriate screening for hereditary cancer syndromes, specifically hereditary breast and ovarian cancer (HBOC) and Lynch syndrome. This RFA suggested that applicants might propose programs that would mitigate disparities in access to genetic services, e.g., by targeting people without insurance or living in rural communities. To some extent, this reflects a growing concern about health inequities among federal health agencies. The Health Resources and Services Administration (HRSA), for example, funds a nationwide network of Regional Genetics Networks to provide clinical services for children with heritable conditions; their 2016 call for proposals explicitly required grantees to "[link] medically underserved populations (based on poverty, rural geographic location, and/or populations that experience health disparities) to genetic service providers, and [promote] efficient genetic services practices through the use of health information technologies such as telehealth/telemedicine."

The SHAs embraced a remarkably similar set of goals in their PHG programs: using surveillance data to estimate the public health burden of hereditary conditions, educating healthcare providers and the public about genetic bases of chronic disease, promoting policies to increase access to clinical genetic services, and collaborating with internal colleagues and external partners to increase capacity.,21,22 However, as we will show, their execution of program objectives varied by state.

In this paper, we employ qualitative methods to explore how program staffers conceptualize health disparities and inequities in the context of precision public health. We find that SHAs have applied a population-level approach to identify high-risk individuals who carry genetic variants that increase risk of disease, but have needed to tailor programs to reflect state-specific health disparities by SES, geography, and race/ethnicity. These insights could inform the development of PHG programs in other states.

\section{MATERIALS AND METHODS}

Our analysis draws on 85 in-depth, semistructured interviews conducted between 2012 and 2017 and program documents (e.g., grant applications, program reports). We recruited interviewees by first contacting and interviewing SHA genomics program staff in each of the three states, who then aided in the recruitment of internal collaborators (i.e., colleagues in the state health agencies) and external partners (e.g., clinicians, patient advocacy groups, third-party payers, and academic researchers). ${ }^{23} \mathrm{We}$ asked about the origins of their genomics-related activities, barriers in integrating genomics in public health programming, and obstacles in partnership formation (a sample interview guide is available in the Supplemental Materials). Because of our interest in health disparities and inequities, the interview guide 
Table 1 Clinical management repertoire of action Illustrative examples of clinical management repertoire of action

1 The Office of Public Health Genomics. A new paradigm shift. (...) To promote- It's not, in genetics, it's not new, this thinking. The term is new. And to promote it this way in public health is new. It was to promote three conditions. You hear about this yet? BRCA, Lynch, familial hypercholesterolemia, that's what I'm going to come to next. To promote these three conditions. Which are all dominant conditions. Very common in our population. And of extreme chronic disease significance because they'd have to do with breast and ovarian cancer, colon cancer, and heart disease. Stroke, perhaps. But anyway - So those three conditions to promote. And also that screening should be done for those. And in certain ways, shapes, and forms. (MI Interview 1-State genomics program staff, 2012)

2 So if you go back to the original premise of the health family tree, it was a population-based approach, albeit in the school setting. And then, identification of those high-risk families. And then really focusing on changing behavior within those high-risk families. So it was the whole, really, spectrum of them, of that process. So population narrowed down to the high risk. Which still makes sense to me. How else do you identify high risk but through a populationbased approach? And there are some that are more cost effective than other approaches to identify those high risks. (UT Interview 1State genomics program staff, 2013)

3 ...it did seem as if, that there's a group that is very aware of family health history. But are they, you know, white, more higher income, well educated, it's that group that would do the 23andMe and have no concerns about privacy. Whereas the people that were less aware of it and less aware of its importance had less frequently collected and therefore shared it with a medical provider. So we take that as saying we've done a good job about getting the word out about family health history because we've been promoting it for about seven, eight years now. But it's been very general. We need to get more targeted. And here again, when you say things like so does this plan kind of help validate work that you're doing? That BRFSS data show us, here's a group that isn't aware of the importance of it, isn't doing it yet. So should that guide some of our efforts? Yeah, we think it should. (CT Interview 1-State genomics program staff, 2014)

specifically asked people to reflect on which subgroups they were most concerned about, and what types of programs they had developed to reach those groups. Of the 89 SHA potential interviewees we identified, 85 agreed to be interviewed (we could not contact 3 of them and 1 declined the invitation). Interviews ranged between 30 and $90 \mathrm{~min}$ in length, and were recorded and transcribed verbatim.

We collected and reviewed 414 program documents from the SHAs (181 in Michigan, 132 in Utah, and 101 in Connecticut). We gathered publicly available documents from the SHAs' websites, including program newsletters and educational materials, such as family health history brochures, and asked SHA staff to share internal documents, such as meeting minutes and grant applications. We reviewed these program documents to understand the details of the SHAs' PHG program activities over the years.

For this article, we approached the data with specific interest in understanding issues relating to health disparities and inequities. We used NVivo 11 (a qualitative software package) to analyze the data. Our first-order coding activities tagged segments of the interview transcripts that corresponded to the topics on the interview guide. We conducted our coding in the spirit of the grounded theory tradition, and added "emergent codes" to capture new themes suggested by the interviewees (e.g., "policy anticipation"). ${ }^{23}$ Second-order coding coalesced those codes into themes (e.g., "Strategies for addressing health disparities/inequities").

\section{RESULTS}

We interviewed 85 people (32 in Michigan, 20 in Utah, and 33 in Connecticut). Genomics program staff in all three states developed two overlapping repertoires of action that guided strategies for identifying high-risk individuals who could benefit from clinical genetic services, which we term a "clinical management repertoire" and a "public health action repertoire." The clinical management repertoire identified high-risk individuals who should be referred for genetic counseling, whereas the public health action repertoire tailored programming to reach subpopulations whose risks are compounded by social vulnerabilities that make it difficult to access screening and treatment services.

Most of the activities executed under the clinical management repertoire conceptualized health disparities primarily in biological terms (i.e., population-level differences in the prevalence of specific variants that increase disease risk); ${ }^{4,24}$ whereas, in the public health action repertoire, strategies were developed to mitigate inequities in access to genomic services (see Table 1). Despite these similarities, there were important differences across states. Most significantly, genomics program staff used state-specific surveillance data to understand their state's demographics, and used this information to tailor their public health action repertoires to the needs of vulnerable subgroups.

\section{Expanding the clinical management repertoire to include public health action}

The SHA genomics programs initially articulated nearly identical priorities. While SHAs do not provide direct clinical care, they disseminate information about best practices for identifying individuals at high risk for hereditary cancers to providers and the public-we term this the clinical management paradigm (see Table 1). Participants very quickly realized, however, that they needed to modify their strategy from a straightforward model of identifying high-risk individuals for intensive clinical management to one that would blend insights on biological health disparities with social vulnerabilities. For example, SHA genomics program staff in Connecticut analyzed survey data about family health history (FHH) education and found that their efforts to educate the public about the importance of knowing one's 
FHH were primarily reaching white, wealthier, and more highly educated members of the public. In response, they developed new outreach programs with community-based organizations that served low-income patient populations and racial and ethnic minorities. ${ }^{25}$ Similarly, when Utah launched its program in 2003, SHA staff recognized the difficulties of accessing genetic services in rural communities. They noted that not only are rural communities less likely to be served by clinical genetic services, in part because of distance from academic medical centers, but the people who live there also tend to be low income and have low levels of educational attainment. When they revived their program in 2014, they constructed much more specific objectives to reduce cancer incidence and mortality in these rural and low-income populations (see Table 2), which aligned with the health disparities objectives suggested in the 2014-2019 CDC RFA. With this amendment, Utah's genomics program strategies evolved from focusing on biological disparities to mitigating health inequities caused by the intersection of biological susceptibility and social vulnerability.

In all three states, integrating the clinical management and public health action repertoires became vitally important to a comprehensive PHG program.

Tailoring the public health action repertoire for their state All three SHAs used information about state-specific social vulnerabilities to tailor information about genomics to patients and providers. These vulnerabilities fell into three main categories: SES, geography, and racial/ethnic identity (see Table 2). They conceptualized these three categories as complex and overlapping challenges, not existing in isolation.

The first and most commonly perceived social vulnerability is SES. Program staff and collaborators in all three states identified factors such as poverty or inadequate insurance coverage as important barriers in accessing clinical genetic services. Echoing the concerns of public health scholars, ${ }^{26}$ one staff member in Connecticut explained that they were especially worried about insufficient healthcare coverage fueling the emergence of health inequities, dividing those who are able to afford genetic services from those who cannot.

Second, SHAs recognized that geographical location poses access barriers to genomic services-this was most especially true in Michigan and Utah. At the time of interview, Michigan SHA program staff noted that residents living in the Upper Peninsula did not have convenient access to a hospital that offered clinical genetic services. Geographical distance is a common barrier in many types of healthcare services, of course, but is especially acute for genetic services, which are usually concentrated in urban settings or academic medical centers. ${ }^{26-28}$ Geographic barriers also turned out to be problematic even in densely populated regions of the country, however, such as Connecticut, where one SHA staff reported that inadequate public transportation makes it difficult for people to see a specialist. Moreover, our participants said that geographic barriers are often compounded by low SES. An external collaborator in Utah (UT
Interview 20, 2017) described some patients as being both "geographically far away" and "financially far away" from any type of cancer treatment services, let alone cancer genetic services.

Third, all three SHAs perceived health inequities by racial and ethnic diversity, but this diversity varied greatly across states, and programs needed to reflect this. For instance, participants in Utah described the challenges of engaging Native Americans, who make up $1.6 \%$ of their population (compared with $0.7 \%$ in Michigan and $0.5 \%$ in Connecticut). ${ }^{29}$ In Michigan, a SHA internal collaborator related the difficulties of "[making] cancer genetics understandable and applicable to low-income people" (MI Interview 15, 2013). As an example, she described how a program designed to encourage breast and cervical cancer screening among lowincome African American women had limited efficacy because of the extreme underrepresentation of African Americans working in the county health department (Table 2). She stated that the low cancer screening participation rates grew even worse after the county dismissed minority outreach workers in the wake of budget cuts. Given these difficulties engaging African American women around conventional cancer screening practices, she anticipated even greater barriers in persuading them to undergo cancer genetic counseling.

Efforts to tailor programming for racial/ethnic minorities were sometimes hindered by the lack of granularity in public health surveillance data. A collaborator working with Connecticut's program said that state-level public health surveillance data often lump groups together (e.g., as "Asians" or "other") and that this may mask the specific problems of racial and ethnic subgroups. For example, although public health data typically portray Asians as very healthy, this masks specific experiences of Cambodians, who are, as this partner claimed, the "the sickest in the country," (CT Interview 27, 2015). Connecticut's staff thus tailored a program to this country-specific group as part of an oral history initiative, ${ }^{25}$ and worked to address the difficulty of collecting $\mathrm{FHH}$ on people whose family members may have died in the Cambodian genocide. In this case, neither a highrisk strategy nor a population-level strategy alone could have addressed the health disparities of Cambodian immigrants; instead, a public health repertoire sensitive to the historical and social vulnerabilities of this group was important to recognizing their unique needs.

\section{Addressing both clinical management and public health action goals}

Because social vulnerabilities varied across states, SHAs devised three main strategies that reflected the demographic needs of their residents while leveraging community-based resources and partnerships (e.g., local advocacy organizations): educating the public, educating providers, and policy anticipation (Table 3 ).

First, SHAs deployed public outreach strategies that specifically engaged underserved populations (Table 3). For 
Table 2 Public health repertoire of action-social vulnerabilities

$\begin{array}{lll}\text { State health } & \text { Identified social } \quad \text { Illustrative examples } \\ \text { agency } & \text { vulnerabilities } & \end{array}$

\begin{tabular}{|c|c|c|}
\hline Michigan & Socioeconomic status & $\begin{array}{l}\text { I think that an awful lot of the disparities }{ }^{a} \text { we see are socioeconomic. And after you got rid of all of that, I } \\
\text { believe that there are still some genetic differences. And I think that those need to be elucidated so that we } \\
\text { can do what we can do on the genomics side and still work. It's very hard to work on the socioeconomic } \\
\text { stressors on the disparities. People don't want to invest in that. (MI Interview 10-State genomics program } \\
\text { staff, 2013) }\end{array}$ \\
\hline
\end{tabular}

Geography

There just aren't enough—aren't enough services. If somebody lives in Washtenaw County in Ann Arbor, access to a genetics counselor is a lot easier than somebody who lives in the Upper Peninsula. They're just, the folks from the genomics department at the state will talk about that all the time. There just aren't enough counselors. (MI Interview 18-County health department, 2014)

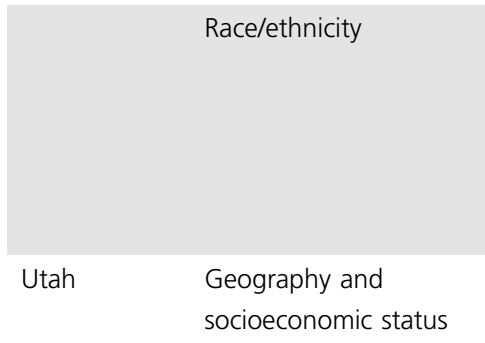

And they were out there working with African American women about trying to get them in for breast and cervical cancer screening. And basically these women said I'm not dealing with that health department anymore. (...) It was just an example of a health department that was just-I went to a meeting. Their county seat is very black. Went to a meeting in their health department. And everyone in the room was white. Everyone in the room was white. And I thought to myself, " $\mathrm{Hm}$, I'm beginning to see what your problem is here." (MI Interview 15-Internal collaborations in cancer, 2013)

So even if you don't have $B R C A$, just getting cancer treatment if you're in a rural area, there's just not enough cancer doctors. I mean, there's enough cancer doctors but there's not enough of a need in a rural area to build a whole cancer area all around it. You know. So if you're lucky enough, like me, to live 10minutes away from a BRCA specialist, that's great. But if you're geographically far away or if you're financially far away, which is a huge amount of people, it's hard to get the care that you need. (UT Interview 20-Community collaborator, 2017)

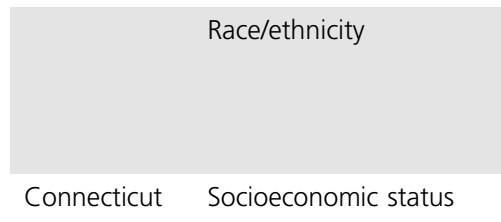

So there's a large Native American population here that we almost never see at our institute. We just-we never see them in cancer genetics. And then we also have a growing Hispanic-we have a large Hispanic population here. I don't know if it's necessarily a lack of outreach that's been going on but we haven't seen a lot of the Hispanic patients come through our clinic as well. (UT Interview 3-Genetic counselor, 2013)

Connecticut Socioeconomic status So even when you read descriptions of Connecticut, it's kind of like the haves and the have-nots. And so there's greater polarity for the income disparity, which of course we know translates into health disparities as well. (...) But again, at the most base-level, we have some very glaring contradictions here as far as socioeconomic availability and affordability of healthcare. (CT Interview 1-State genomics program staff, 2014)

\begin{tabular}{|c|c|}
\hline $\begin{array}{l}\text { Geography and race/ } \\
\text { ethnicity }\end{array}$ & $\begin{array}{l}\text { Transportation is a big issue. And I know this is just an aside but it's just to underscore the point. Last week, a } \\
\text { group of Southeast Asian folks who have a very tight knit community, Cambodian, Vietnamese, Laotian, } \\
\text { come here. Refugees. (...) And they came in to advocate for greater services. So, they had a meeting and I } \\
\text { was invited just to sit in and listen to what some of the issues were. Mostly because the person they were } \\
\text { meeting with wanted me to consider them for one of the family health history projects. (...) At any rate, the } \\
\text { two pieces they talked about were language difficulties still and transportation. (CT Interview 1-State } \\
\text { genomics program staff, 2014) }\end{array}$ \\
\hline Race/ethnicity & $\begin{array}{l}\text { Another huge issue for is the inequity in data. So we're waiting, we're very excited about genomic projects } \\
\text { because it's almost impossible to get the state or the federal government to collect data broken down to } \\
\text { ethnicities. They do black, white, Hispanic, non-Hispanic. And what does that tell you? I've been told recently } \\
\text { Asians were "others." (...) So now they're saying Asians are the healthiest population in the United States. } \\
\text { And we're saying yeah, but if you look at our community, they're the sickest in the country and you have no } \\
\text { data on them because it's not granular enough. (CT Interview 27-Community collaborator, 2015) }\end{array}$ \\
\hline
\end{tabular}

${ }^{a}$ Here, the participant uses "disparities" to mean inequity. To West et al.'s point, two meanings of disparities are often conflated and confused within genomics: (1) population genetic variation and (2) inequities that describe the differences in health outcome because of social vulnerabilities and disadvantage. We find this confusion in many other interviews with participants and rely on context to make sense of the term's usage

instance, the Michigan SHA collaborated with Healthy Homes University, a Department of Housing and Urban Development program that addresses health and safety issues in low- and very low-income households. ${ }^{30}$ They incorporated $\mathrm{FHH}$ questions into home visit interviews concerning asthma. $^{30,31}$ One participant reported that this not only helped educate families about chronic illness, risk, and behavioral change, but also identified particularly sick families for intensive intervention and remediation to reduce asthma and allergy triggers. ${ }^{30,31}$ Similarly, Connecticut's SHA worked 
Table 3 Strategies to address clinical management and public health action repertoires

\begin{tabular}{|c|c|c|c|}
\hline rategy & Michigan & Utah & Connecticut \\
\hline $\begin{array}{l}\text { Education } \\
\text { of the } \\
\text { public }\end{array}$ & $\begin{array}{l}\text { He would ask a question. "My dad has it, } \\
\text { my grandma has it." Well, it's known to be } \\
\text { a family history chronic disease. And } \\
\text { explaining what chronic disease means. } \\
\text { Because most people, it's episodic to them. } \\
\text { So even though it comes and goes, they } \\
\text { don't recognize it's always there. It's really } \\
\text { hard to explain to some folks. It was hard for } \\
\text { me to grasp at first too. So [family history] } \\
\text { did help me explain that chronic disease } \\
\text { piece too. Kind of played a part. So I think it } \\
\text { was most helpful in the relationship with the } \\
\text { family. Behavior change. (MI Interview 13- } \\
\text { Internal collaborator, 2013) }\end{array}$ & $\begin{array}{l}\text { And so our role in that was pulling together } \\
\text { the Pacific Islander community and the } \\
\text { Hispanic community to come in and test } \\
\text { these materials. And we worked extremely } \\
\text { closely with [collaborator] and the group } \\
\text { that develops these materials with what we } \\
\text { call master teachers. To say these are the } \\
\text { concepts that we want people to know } \\
\text { about. And she tied it into the state } \\
\text { curriculum for health and science and } \\
\text { national curriculum standards... (UT } \\
\text { Interview 1-State genomics program staff, } \\
\text { 2013) }\end{array}$ & $\begin{array}{l}\text { Well, we are here because it's helping, like } \\
\text { [colleague] was saying, to change the social } \\
\text { determinants of health. So being able to } \\
\text { educate families about what they should } \\
\text { know about their health history and sharing } \\
\text { among themselves. And so they can know } \\
\text { better what they can prevent or what they } \\
\text { can do differently to actually stay healthy. } \\
\text { (CT Interview 29-Community collaborator, } \\
\text { 2014) }\end{array}$ \\
\hline $\begin{array}{l}\text { Education } \\
\text { of } \\
\text { providers }\end{array}$ & $\begin{array}{l}\text { But [the CDC is] funding the work we've } \\
\text { done to try to identify early onset cancers } \\
\text { that have a probable genetic component } \\
\text { and alerting hospitals to that, those } \\
\text { patients. And recently, alerting their } \\
\text { physicians to make sure they get the } \\
\text { counseling they need. (...) So I kind of like- } \\
\text { and the other point is of course, that you're } \\
\text { really educating the physician. So the next } \\
\text { patient that comes up that fits the criteria, } \\
\text { they'll get it right away. We don't have to } \\
\text { send out a note. Anyway, I just see it's kind } \\
\text { of like improving the whole healthcare } \\
\text { delivery process. (MI Interview } 8 \text { - Internal } \\
\text { collaborator, 2013) }\end{array}$ & $\begin{array}{l}\text { I haven't looked at them for a long time but } \\
\text { I think, doesn't it just say "if you have a } \\
\text { family history, your risk increases?" Just as } \\
\text { basic as it can be? I think that's probably } \\
\text { enough information. And I think it's enough } \\
\text { to say-for them to trigger the conversation } \\
\text { if they get to see a doctor or a diabetes } \\
\text { educator or another health professional, } \\
\text { saying "what is my increased risk?" But I } \\
\text { think some people don't even recognize } \\
\text { that if they have a family history, they really } \\
\text { don't have to get diabetes. Or they really do } \\
\text { have an increased risk. I think sometimes it's } \\
\text { meaningless information. (UT Interview } 12 \\
\text { — Internal collaborator, 2013) }\end{array}$ & $\begin{array}{l}\text { The [Cambodian Survivor Health } \\
\text { Assessment Tool] was developed in the early } \\
\text { 1990s with funding from the Office of } \\
\text { Minority Health. And Dr. [X], our doctor, } \\
\text { was the head of that project. And basically it } \\
\text { was done using a community-based } \\
\text { participatory approach. So we went over the } \\
\text { stories, the general stories of trauma history, } \\
\text { and we put together a questionnaire. The } \\
\text { physical symptoms and stuff came from } \\
\text { healthcare providers and we did a review of } \\
\text { what generally went into a health } \\
\text { questionnaire and into a family history. And } \\
\text { then it was translated. (CT Interview 27- } \\
\text { Community collaborator, 2015) }\end{array}$ \\
\hline $\begin{array}{l}\text { Policy } \\
\text { anticipation }\end{array}$ & $\begin{array}{l}\text { And we can't pay for genetic counseling } \\
\text { because the Breast and Cervical Program } \\
\text { doesn't pay for that. The Breast and Cervical } \\
\text { Program can't pay for BRCA testing either. } \\
\text { There's been an enormous fight about } \\
\text { whether Medicaid can pay for BRCA testing. } \\
\text { Right now, they'll do it on a case by case } \\
\text { basis. That took some doing because } \\
\text { before, they wouldn't do it. So this is the } \\
\text { trouble with being in poor America. You've } \\
\text { got these fragmented services, you've got } \\
\text { these half-baked services. (MI Interview } 15 \\
\text {-Internal collaborator in cancer, 2013) }\end{array}$ & $\begin{array}{l}\text { We are not a state that has expanded } \\
\text { Medicaid. What we have quote expanded } \\
\text { has been ridiculously small. So we have a lot } \\
\text { of people who are struggling to meet } \\
\text { financial needs with their healthcare. Maybe } \\
\text { also a lack of education, I don't know about } \\
\text { the general public and maybe some } \\
\text { professional people too, about some of the } \\
\text { benefits of prevention and testing and early } \\
\text { intervention. We have a culture here that a } \\
\text { lot of people believe more in holistic or } \\
\text { denial [laughs] or a combination of both. So } \\
\text { that's quite frustrating. Probably also a lack } \\
\text { of local legislative support for anything } \\
\text { innovative when it comes to medical. (UT } \\
\text { Interview 13-Internal collaborator, 2017) }\end{array}$ & $\begin{array}{l}\text { Some other things that Michigan has done } \\
\text { as far as working more closely and } \\
\text { interacting with the payers, that was of } \\
\text { great interest to us. [One genetics program } \\
\text { staff] has said in the past, we just have to } \\
\text { watch where the Affordable Care Act goes. } \\
\text { Because then that may take care of that } \\
\text { without having to spend money to be a } \\
\text { sponsor at the annual insurance convention } \\
\text { and provide, you know, a crystal award to } \\
\text { everybody or something. (CT Interview 1- } \\
\text { State genomics program staff, 2014) }\end{array}$ \\
\hline
\end{tabular}

with four community groups to disseminate tailored $\mathrm{FHH}$ information. ${ }^{25}$ In Utah, one collaborator described the Salt Lake City school district as "minority majority" because some schools are "sixty-five percent Hispanic Latino and the rest of it 'other.' There are schools with a hundred and two languages spoken" (UT Interview 8, 2013). Accordingly, in partnership with the SHA staff, collaborators consulted with Pacific Island and Hispanic communities to develop a culturally relevant $\mathrm{FHH}$ school curriculum that would engage a diverse student body and their families. For example, in a game to teach Hispanic fifth graders and their families about inherited physical traits, community members suggested renaming the 
"hitchhiker's thumb" (thumbs that bend backwards) to "thumb extension," because of cultural stigmas associated with hitchhiking (UT Interview 8, 2013).

Second, SHAs educated healthcare providers, because providers play a pivotal role in determining patient risk. They especially focused on developing programs for providers who could not readily consult with medical geneticists, such as primary care providers in rural communities. ${ }^{28}$ Michigan created a Cancer Family History Guide, Utah hosted retreats for providers to learn about hereditary cancer syndromes, and Connecticut organized workshops on how to use $\mathrm{FHH}$ screening to quickly identify "red flags" that would warrant referring a patient to a genetics provider.

We term the third strategy "policy anticipation," which reflects to some degree their frustration at their inability to directly tackle some SES-related barriers. For example, participants from all three states identified insurance coverage as necessary to achieving equitable access to services, but also felt that they have limited ability to directly influence health insurance coverage, placing them in a position of hopeful anticipation. At the time of most interviews, none of the three states had yet embraced Medicaid expansion under the Affordable Care Act (Michigan and Connecticut would in 2014; Utah never did). Notwithstanding some uncertainties about its impact, the prospect of Medicaid expansion presented a potential pathway to increasing comprehensive healthcare coverage and thus removing at least some of the financial barriers that individuals may encounter in seeking genetic services. One genetic counselor in Utah (which did not expand Medicaid) likened efforts to get Medicaid coverage for genetic testing to "a roller coaster ride," which depended on the whims of the state Medicaid director. In Michigan, as they waited for Medicaid expansion to take effect, the SHA worked to expand health plan coverage by encouraging payers to cover HBOC screening in accordance with the US Preventative Services Task Force (USPSTF) recommendations. As a result, between 2008 and 2011, they increased the number of health plans that would cover HBOC screening (as consistent with USPSTF Grade B BRCA recommendation). ${ }^{32}$ Despite this success in expanding access to HBOC screening for people covered by private insurers, they also continued to hope for Medicaid expansion, to reduce barriers that low-income patients might face in accessing genetic services.

\section{Barriers in program implementation}

Despite developing these multivalent strategies, the SHA staff lamented that remedying some barriers relating to underlying social vulnerabilities are simply beyond the purview of public health's jurisdiction, resources, and impact.

...But there's a few things I think that relate to public health that aren't necessarily, they're not really health. But things that we have to address, would be the disparities. We have some of the richest, wealthiest parts of the country but then we also have some of the poorest. So, some of those disparities I think need to be addressed before we can even get to the health issue. (CT Interview 12, 2014)

Another participant acknowledged that social disparities pose challenges to patients along the entire continuum of care in chronic disease prevention. While it may be possible to translate and tailor educational materials to bring $\mathrm{FHH}$ education to Hispanics, one outreach worker in Utah worried that migrant workers, for example, who might benefit from genetic counseling and/or testing may not be able to receive recommended services.

And then of course, now what do I do with this information? Now that I know all this family history, what do I do with it? ... The purpose [of our research project] was really to see if we could introduce $\mathrm{FHH}$ into this population, not what do you do with it once you've got it. And again, I appreciate that research questions have to have a very focused direction. But I also remember thinking, okay, there's a step number two that people just jumped off of a cliff and didn't get services. (UT Interview 4, 2013)

In some cases, state SHA staff questioned the utility of educating about $\mathrm{FHH}$, if the larger healthcare system could not provide the patient with comprehensive preventive care.

\section{DISCUSSION}

SHA genomics program staff and collaborators recognized the utility and inadequacies of Rose's two prevention frameworks. Accordingly, they embraced a population-level approach to identify high-risk individuals, but realized that if they also wanted to forestall the emergence of health inequities, they would need to tailor those strategies to address the specific social, political, and economic vulnerabilities of their states' populations. While they endorsed the clinical management objectives articulated in best practice recommendations for genomic medicine, they realized that national-level guidelines do not address ways to manage the social barriers relating to SES, geography, and racial/ethnic minority status. As a result, they devised a complementary public health repertoire of action that would address specific barriers faced by their citizens. Because these challenges varied across states, the strategies and programs they devised also varied. Notwithstanding this innovative spirit to tackle state-specific health disparities, SHA staff and collaborators lamented the nonnegotiable limits of their capacity to reach underserved populations, such as the lack of resources or broader political will that would make equitable access to genomic medicine a reality.

We illustrate how PHG programs cannot be applied universally; rather, states could learn from some examples and best practices that other states have employed, but must modify programs in light of local characteristics and resources. This requires conceptualizing populations in a 
more granular way than Rose does, wherein he approaches population around a single mean distribution, with a morbidity or mortality rate that is a simple average of the total. Indeed, other public health scholars have criticized Rose's use of "populations" and "individuals" because he ignores the characteristics of and social relations between groups. Razak et al. argue that focusing on population averages, conceptualizes populations as coherent entities. ${ }^{33}$ They warn that this perspective is likely to overlook the differential needs of subpopulations. Relatedly, Krieger contends that relying on population means is problematic because it ignores substantive properties that are important to generating meaningful information about subgroups. ${ }^{34}$ Corroborating these concerns, the SHA genomics program staff and collaborators we interviewed understand that it is impossible to advance health equity without accounting for population heterogeneity. Our findings show that not only are SHAs critical partners in disseminating and implementing genomic innovations, but that they also have valuable local knowledge about the vulnerabilities and needs of their constituencies.

Over the past few years, other states have expressed interest in moving forward with PHG programs, but have not necessarily had abundant resources to do so. The CDC's Office of Public Health Genomics has created an online repository of material from the states they have funded (including the three states described in this study). In 2014, they launched a clickable map, ${ }^{35}$ making it easy for people in SHAs to identify potential partners in their state (e.g., genetics providers with clinical expertise, patient advocates). While these templates and resources are useful starting points for states that are just beginning work in this area, it is important to remember the main finding from this study, which is that states need to develop a public health management repertoire of action that will be locally relevant to the demographic profiles of their states, to anticipate and address vulnerabilities that may be specific to their own citizens. For this reason, states that wish to begin work on PHG would do well to start by mining some of their state-specific surveillance data (e.g., cancer registry, vital records) to understand the public health burden of hereditary conditions and the patterns of social vulnerabilities in their state. They would also do well to reach out to partners who serve medically underserved populations in their state, however they define that. While the CDC and HRSA have identified certain disparities as sources for concern (e.g., poverty, rural geographic location), public health staff in each state should also survey the landscape for other types of social vulnerabilities that may make it difficult to access clinical services. They may, for example, need to partner with organizations that serve racial and ethnic minorities, refugee and immigrant populations, or people with low levels of educational attainment.

Burton et al. proposed a "stratified prevention strategy" to adapt Rose's frameworks for the demands of genomic medicine and precision public health. ${ }^{10}$ Our findings show, however, that a stratified approach could potentially exacerbate health inequities unless the definition of subgroups is guided by information on existing health status and vulnerabilities. The perspectives presented in this study illustrate how levels of intervention are interdependent. The challenges faced by the SHA staff and collaborators we interviewed could not be resolved at the level of public health programming alone. As Frieden proposes, improving longterm population health requires synergistic intervention at multiple levels of health impact. ${ }^{17}$ Thus, to improve the equity and impact of public health prevention strategies, fundamental causes of disease that are beyond the purview of public health should also be addressed at a structural level. ${ }^{17}$

\section{ELECTRONIC SUPPLEMENTARY MATERIAL}

The online version of this article (https://doi.org/10.1038/s41436018-0056-y) contains supplementary material, which is available to authorized users.

\section{ACKNOWLEDGEMENTS}

This material is based upon work supported by the National Human Genome Research Institute of the National Institutes of Health, under award number 1K01HG006441-01A1. Any opinions, findings, conclusions, or recommendations expressed in this publication are those of the author(s) and do not necessarily reflect the view of the National Institutes of Health. The authors thank two anonymous reviewers for comments on drafts of this paper, and Pilar Ossorio, Daniel Kleinman, and Deb Franko for guidance on the execution of the research.

\section{DISCLOSURE}

The authors declare no conflicts of interest.

\section{REFERENCES}

1. Roberts MC, Kennedy AE, Chambers DA, et al. The current state of implementation science in genomic medicine: opportunities for improvement. Genet Med. 2017;19:858-63.

2. Trivers K, Rodriguez J, Cox S, et al. The activities and impact of state programs to address hereditary breast and ovarian cancer, 2011-2014. Healthcare. 2015;3:948-63.

3. Khoury MJ, Bowen MS, Clyne M, et al. From public health genomics to precision public health: a 20-year journey. Genet Med. 2018:20;574-82.

4. West KM, Blacksher E, Burke W. Genomics, health disparities, and missed opportunities for the nation's research agenda. JAMA. 2017;317: 1831-2.

5. Carter-Pokras O, Baquet C. What is a "health disparity"? Public Health Rep. 2002;117:426-34.

6. Whitehead $M$. The concepts and principles of equity in health. Int J Health Serv. 1992;22:429-45.

7. Rose G. Sick individuals and sick populations. Int J Epidemiol. 1985;14: 32-38.

8. Rose G. The strategy of preventive medicine. Oxford University Press; New York, 1992.

9. US Preventive Services Task Force. BRCA-related cancer: risk assessment, genetic counseling, and genetic testing. Recommendations for primary care practice. 2013. https://www.uspreventiveservicestaskforce.org/Page/ Document/UpdateSummaryFinal/brca-related-cancer-risk-assessmentgenetic-counseling-and-genetic-testing. Accessed 11 June 2018.

10. Burton H, Sagoo GS, Pharoah P, et al. Time to revisit Geoffrey Rose: strategies for prevention in the genomic era. Ital J Public Health. 2012;9: e8665-8661.

11. Doyle YG, Furey A, Flowers J. Sick individuals and sick populations: 20 years later. J Epidemiol Community Health. 2006;60:396-8. 
12. Frohlich $\mathrm{KL}$, Potvin $\mathrm{L}$. The inequality paradox: the population approach and vulnerable populations. Am J Public Health. 2008;98:216-21.

13. Forman $A D$, Hall MJ. Influence of race/ethnicity on genetic counseling and testing for hereditary breast and ovarian cancer. Breast J. 2009;15: S56-S62.

14. Institute of Medicine. Implications of genomics for public health. National Academies Press (U.S.); Washington DC, 2005.

15. Khoury MJ,Gwinn M,Burke W, et al. Will genomics widen or help heal the schism between medicine and public health?. Am J Prev Med. 2007;33:310-7.

16. McLaren L, Mclntyre L, Kirkpatrick S. Rose's population strategy of prevention need not increase social inequalities in health. Int J Epidemiol. 2010;39:327-77.

17. Frieden TR. A framework for public health action: the health impact pyramid. Am J Public Health. 2010;100:590-5.

18. Phelan JC, Link BG, Feldman NM. The genomic revolution and beliefs about essential racial differences: a backdoor to eugenics? Am Sociol Rev. 2013;78:167-91.

19. Cragun D, Bonner D, Kim J, et al. Factors associated with genetic counseling and BRCA testing in a population-based sample of young Black women with breast cancer. Breast Cancer Res Treat. 2015;151:169-76.

20. Health Resources and Services Administration. Funding opportunity announcement: regional genetics networks (HRSA-17-082). In: Maternal and Child Health Bureau Division of Services for Children with Special Health Needs. US Department of Health and Human Services; Rockville, Maryland, 2016.

21. St Pierre J, Bach J, Duquette D, et al. Strategies, actions, and outcomes of pilot state programs in public health genomics, 2003-2008. Prev Chronic Dis. 2014;11:E97.

22. Senier $L$, Lee $R$, Nicoll $L$. The strategic defense of physician autonomy: state public health agencies as countervailing powers. Soc Sci Med. 2017;186:113-21

23. Charmaz K. Constructing grounded theory. 2nd ed. SAGE Publications Ltd.; London, 2014.

24. Sankar P, Cho MK, Condit CM, et al. Genetic research and health disparities. JAMA. 2004;291:2985-9.
25. Senier L, Shields M, Lee R, et al. Community-based family health history education: the role of state health agencies in engaging medically underserved populations in understanding genomics and risk of chronic disease. Healthcare. 2015;3:995-1017.

26. Hawkins AK, Hayden MR. A grand challenge: providing benefits of clinical genetics to those in need. Genet Med. 2011;13:197-200.

27. Chan L, Hart LG, Goodman DC. Geographic access to health care for rural Medicare beneficiaries. J Rural Health. 2006:22:140-6.

28. Senier L, Kearney M, Orne J. Using public-private partnerships to mitigate disparities in access to genetic services: lessons from Wisconsin. Adv Med Sociol. 2015;16:269-305.

29. United States Census Bureau. Quick facts. United States Census Bureau; Washington DC, 2010.

30. Wisinski C, Gehring J, Stewart L, et al. Healthy Homes University: an innovative approach to indoor air quality, asthma, and family history in a community setting. Public Health Genomics Program: Publications and Presentations 2007; Poster. http://www.michigan.gov/documents/mdch/ HHU_poster_final_final_212469_7.pdf. Accessed 11 June 2018.

31. Largo TW,Borgialli M,Wisinski CL, et al. Healthy Homes University: a home-based environmental intervention and education program for families with pediatric asthma in Michigan. Public Health Rep. 2011;126 Suppl 1:14-26.

32. Duquette $D$, Lewis $K, M c L o s k y ~ J$, et al. Using core public health functions to promote BRCA best practices among health plans. Public Health Genomics. 2012;15:92-97.

33. Razak F, Smith GD, Subramaniam S. The idea of uniform change: is it time to revisit a central tenet of Rose's "strategy of preventive medicine"? Am J Clin Nutr. 2016;104:1497-507.

34. Krieger N. Who and what is a "population"? Historical debates, current controversies, and implications for understanding "population health" and rectifying health inequities. Milbank Q. 2012;90:634-81.

35. Centers for Disease Control and Prevention. State public health genomics program map. Public Health Genomics Knowledge Base (v3.1). 2017. https://phgkb.cdc.gov/PHGKB/stateMapStartPage.action. Accessed 11 June 2018. 